\title{
Numerical study of a novel micro-diaphragm flow channel with piezoelectric device for proton exchange membrane fuel cells
}

\author{
H.K. Ma*, S.H. Huang, B.R. Chen, L.W. Cheng \\ Department of Mechanical Engineering, National Taiwan University, No. 1, Sec. 4, Roosevelt Road, Taipei 10617, Taiwan, ROC \\ Received 14 January 2008; received in revised form 4 February 2008; accepted 4 February 2008 \\ Available online 10 March 2008
}

\begin{abstract}
Previous studies have shown that the amplitude of the vibration of a piezoelectric (PZT) device produces an oscillating flow that changes the chamber volume along with a curvature variation of the diaphragm. In this study, an actuating micro-diaphragm with piezoelectric effects is utilized as an air-flow channel in proton exchange membrane fuel cell (PEMFC) systems, called PZT-PEMFC. This newly designed gas pump, with a piezoelectric actuation structure, can feed air into the system of an air-breathing PEMFC. When the actuator moves outward to increase the cathode channel volume, the air is sucked into the chamber; moving inward decreases the channel's volume and thereby compresses air into the catalyst layer and enhancing the chemical reaction. The air-standard PZT-PEMFC cycle is proposed to describe an air-breathing PZT-PEMFC. A novel design for PZT-PEMFCs has been proposed and a three-dimensional, transitional model has been successfully built to account for its major phenomena and performance. Moreover, at high frequencies, PZT actuation leads to a more stable current output, more drained water, higher sucked air, higher hydrogen consumption, and also overcomes concentration losses.
\end{abstract}

(C) 2008 Elsevier B.V. All rights reserved.

Keywords: Piezoelectric effect; PZT-PEMFC; Micro-diaphragm; Air-breathing; Current generation

\section{Introduction}

Previous studies have shown that air-breathing proton exchange membrane fuel cells (PEMFCs) are lighter in weight because they do not require an additional oxygen feeding device. In addition, the performance of air-breathing PEMFCs, due to oxygen transport limitations, is proportional to the oxygen transfer coefficient [1]. Santa Rosa et al. [2] developed an open-air cathode PEMFC stack with forced air convection instead of natural convection. The stack performance had an optimum performance for the air fan voltage supply at $5.0 \mathrm{~V}$ when using an air fan for combined oxidant supply and stack cooling. Zhang et al. [3] presented a comprehensive numerical analysis on the various stack and cell parameters for stack designs with an array of air-breathing fuel cell cartridges. Matamoros and Bruggemann [4] showed that dehydrating phenomena slightly affected the performance of air-breathing PEMFCs.

\footnotetext{
* Corresponding author. Tel.: +886 223629976; fax: +886223631755.

E-mail address: skma@ntu.edu.tw (H.K. Ma).
}

In general, catalyst loading, relative humidity, temperature, hydrogen stoichiometry, gas diffusion layer (GDL) thickness, and cathode structure are all important factors in the performance of air-breathing PEMFCs [5,6]. Previous studies [7,8] have indicated that interdigitated flow fields force the reactant gas to pass the catalyst layer, which increases the rate of chemical reaction and the performance of fuel cells, thereby reducing the flooding phenomena. Thus, in this study the interdigitated flow field is applied as the anode channel. Li et al. [9] presented the design of a flow field in a bi-polar plate, which is one of the key components in PEMFC stacks; it performs a number of essential functions in stack operation, such as supplying reactants to the cell-active area, current collection, mechanical support to the membrane electrode assembly (MEA), and water and heat management, as well as the maintenance of the separate reactants.

Micro-pumps have been developed with several actuation methods, such as piezoelectric, electromagnetic, shape memory alloy, electrostatic, and thermo-pneumatic devices [10-18]. Most have complex structures and low pumping rates. However, piezoelectric actuation has the advantages of having a relatively simple structure and low power consumption. Micro-diaphragm 


\begin{tabular}{|c|c|}
\hline \multicolumn{2}{|c|}{ Nomenclature } \\
\hline$a_{i}^{\prime}$ & stoichiometric coefficient of the products \\
\hline$a_{i}^{\prime \prime}$ & stoichiometric coefficient of the reactants \\
\hline$A_{\text {in }}$ & inlet area $\left(\mathrm{m}^{2}\right)$ \\
\hline$A_{\mathrm{PZT}}$ & Piezoelectric area $\left(\mathrm{m}^{2}\right)$ \\
\hline$[A / V]_{\mathrm{eff}}$ & effective surface to volume ratio $\left(\mathrm{m}^{-1}\right)$ \\
\hline$D_{\text {eff }}$ & effective diffusion coefficient $\left(\mathrm{m} \mathrm{s}^{-1}\right)$ \\
\hline$f$ & frequency of PZT $(\mathrm{Hz})$ \\
\hline$F$ & Faraday constant $\left(96,439 \mathrm{C} \mathrm{mole}^{-1}\right)$ \\
\hline$h$ & enthalpy (KJ) \\
\hline$i$ & current (A) \\
\hline$j_{0}$ & $\begin{array}{l}\text { reference current density at a known open circuit } \\
\text { voltage }\left(\mathrm{A} \mathrm{m}^{-3}\right)\end{array}$ \\
\hline$j_{\mathrm{T}}$ & transfer current $(\mathrm{A})$ \\
\hline$J_{\mathrm{i}}$ & species diffusive flux $\left(\mathrm{mol} \mathrm{m}^{-2} \mathrm{~s}\right)$ \\
\hline$k_{\text {eff }}$ & effective thermal conductivity $\left(\mathrm{W} \mathrm{m}^{-1} \mathrm{~K}^{-1}\right.$ ) \\
\hline$M$ & Mass (kg) \\
\hline$N$ & amount of species \\
\hline$P_{0}$ & atmosphere pressure $\left(\mathrm{N} \mathrm{m}^{-2}\right)$ \\
\hline$R$ & gas constant $\left(\mathrm{J} \mathrm{mol}^{-1} \mathrm{~K}^{-1}\right)$ \\
\hline$t$ & time $(s)$ \\
\hline$T$ & temperature $(\mathrm{K})$ \\
\hline$V_{\mathrm{a}}$ & anode inlet velocity $\left(\mathrm{m} \mathrm{s}^{-1}\right)$ \\
\hline$V_{\mathrm{c}}$ & cathode inlet velocity $\left(\mathrm{m} \mathrm{s}^{-1}\right)$ \\
\hline$V_{\mathrm{PZT}}$ & $\begin{array}{l}\text { motion equation of the piezoelectric device } \\
\left(\mathrm{m} \mathrm{s}^{-1}\right)\end{array}$ \\
\hline$\forall$ & volume $\left(\mathrm{m}^{3}\right)$ \\
\hline$Y_{i}$ & mass fraction of $i$ th species \\
\hline \multicolumn{2}{|c|}{ Greek symbols } \\
\hline$\alpha_{\mathrm{a}}, \alpha_{\mathrm{c}}$ & $\begin{array}{l}\text { kinetic constants which is drawn by Tafel curve } \\
\text { through the experiments }\end{array}$ \\
\hline$\alpha_{k}$ & concentration exponents \\
\hline$\delta$ & diffusion length (m) \\
\hline$\varepsilon$ & porosity \\
\hline$\eta$ & over potential $(\mathrm{V})$ \\
\hline$\kappa$ & permeability $\left(\mathrm{m}^{2}\right)$ \\
\hline$\rho_{\mathrm{c}}$ & channel air density $\left(\mathrm{kg} \mathrm{m}^{-3}\right)$ \\
\hline$\rho_{0}$ & atmosphere air density $\left(\mathrm{kg} \mathrm{m}^{-3}\right)$ \\
\hline$\sigma$ & electrical conductivity $(\Omega \mathrm{m})$ \\
\hline$\tau$ & shear stress $\left(\mathrm{N} \mathrm{m}^{-2}\right)$ \\
\hline$\varphi$ & potential $(\mathrm{V})$ \\
\hline$\varphi_{f}$ & porous (or liquid) potential $(\mathrm{V})$ \\
\hline$\varphi_{\mathrm{s}}$ & solid potential $(\mathrm{V})$ \\
\hline$\omega_{i}$ & $\begin{array}{l}\text { production rates }\left(\mathrm{kg} \mathrm{m}^{-3} \mathrm{~s}^{-1}\right) \omega \text { angular velocity } \\
\left(\mathrm{rad} \mathrm{s}^{-1}\right)\end{array}$ \\
\hline$[\Lambda]$ & $\begin{array}{l}\text { molar concentration of reactant in porous medium } \\
(\mathrm{mol})\end{array}$ \\
\hline
\end{tabular}

pumps are classified based on the presence or absence of valves $[19,20]$. A plastic micro-pump with a valve is capable of pumping both liquid and gas at a pumping rate of $2 \mathrm{ml} \mathrm{min}^{-1}$ for water and up to $50 \mathrm{ml} \mathrm{min}^{-1}$ for air when the actuation frequency is between 2 and $500 \mathrm{~Hz}$ [21]. A gas pump with a

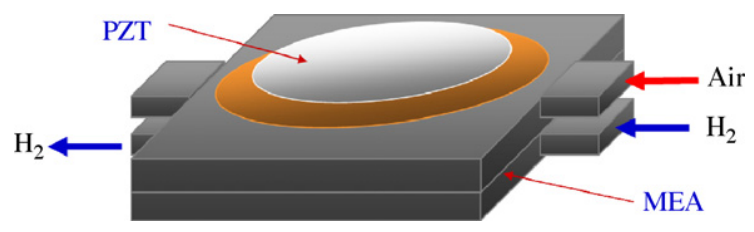

Fig. 1. The outlook of a PZT-PEMFC system.

novel bimorph actuation structure can also feed air into the micro-direct methanol fuel cell (DMFC) [22]. These results showed that the air-diaphragm pump worked at a flow rate of $85.3 \mathrm{ml} \mathrm{min}^{-1}$ in resonance with $3.18 \mathrm{~mW}$, and at a low-power consumption of below $20 \mathrm{~V}$. A new design of a one-side actuating micro-diaphragm pump with PZT was successfully developed that exploited the harmonic resonance of the working liquid with the other system components (valve and diaphragm) in the pump chamber [23]. The maximum flow rate for the newly designed pump reached $72 \mathrm{ml} \mathrm{min}^{-1}$ at the zero pump head in the operation frequency range of $70-180 \mathrm{~Hz}$ [24].

The flow channel, gas diffusion layer, catalyst layer and membrane all influence PEMFC performance. During PEMFC operation, especially at low stoichiometry, liquid water is likely to appear in the cathode, reducing oxygen diffusion. In the membrane, water is transported by electro-osmotic drag, backdiffusion, and convection. Yi and Nguyen [25] showed that the performance of a PEMFC could be improved by anode humidification and positive differential pressure between the cathode and anode, to increase the back transport rate of water across the membrane. Ge and Yi [26] predicted that the dry reactant gases can be successfully humidified internally and maintain high performance when PEMFC is operated in the counterflow mode without external humidification. The electro-osmotic drag coefficient has been found to be a function of the water content of the membrane and temperature [27-30]. Generally, the electroosmotic drag coefficient increases with increasing water content in the membrane. At high water content, the electro-osmotic drag coefficient increases with increasing temperature. Thus, water and thermal management is a key to successful PEMFCs, especially to PZT-PEMFCs. In this study, a novel design of a micro-diaphragm flow channel with piezoelectric device for PEMFCs is proposed. A transitional three-dimensional model [31] is presented to calculate the performance of PEMFCs at different PZT frequencies.

\section{Mechanisms of PZT-PEMFC}

The actuating micro-diaphragm with piezoelectric effects is utilized as one of the flow-channel PEMFC systems, termed the PZT-PEMFC, shown in Fig. 1. This newly designed gas pump with a piezoelectric actuation structure can feed air into the system of an air-breathing PEMFC. While the actuator is moving outward to increase the cathode channel volume, the air is sucked into the chamber; when moving inward to decrease the cathode channel volume, the air is compressed into the catalyst layer and the chemical reaction is enhanced, as shown in Fig. 2. 


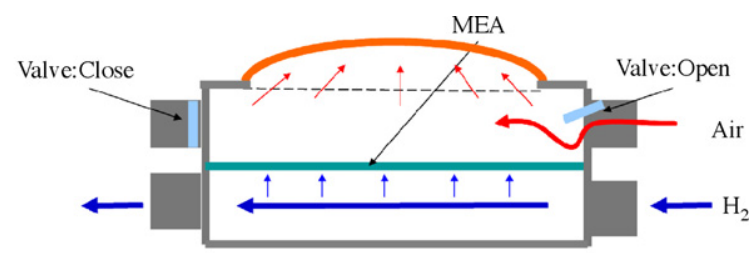

(a) Sucked air into the channel

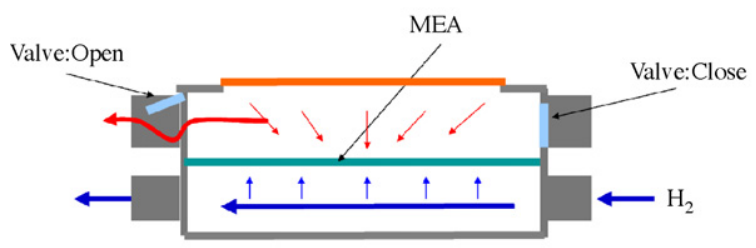

(b) Rejected gases out of the channel

Fig. 2. Actuating mechanisms in a PZT-PEMFC system.

\subsection{Air-breathing PZT-PEMFC cycle}

The air-standard PZT-PEMFC cycle, shown in Fig. 3, is an ideal cycle that describes the processes of an air-breathing PZTPEMFC. Process 1-2 is an expansion process as the PZT moves outward. The pressure in the cathode channel is lower than the atmospheric pressure, $P_{0}$. In the constant volume process $2-3$, air is sucked into the cathode channel at a lower pressure. Process 3-4 is a compression process where the PZT moves inward and the increasing pressure compresses more oxygen into the catalyst layer. In the constant volume process $4-1$, water vapor and un-reacted reactants are pumped out from the cathode channel.

\subsection{Actuation analysis of PZT-PEMFC}

The driving forces at the anode and cathode inlets are different. Inlet hydrogen velocity at the anode is assumed to be constant. On the other hand, inlet air velocity at the cathode is driven by PZT vibrations. The equation of PZT motion is assumed to be the step function shown in the following equation:

$\vec{V}_{\mathrm{PZT}}=\frac{\mathrm{d}}{\mathrm{d} t}\left\{-0.0005 \times \operatorname{STEP}\left[\sin \left(2 \pi \omega t-\frac{\pi}{2}\right)\right]\right\}$

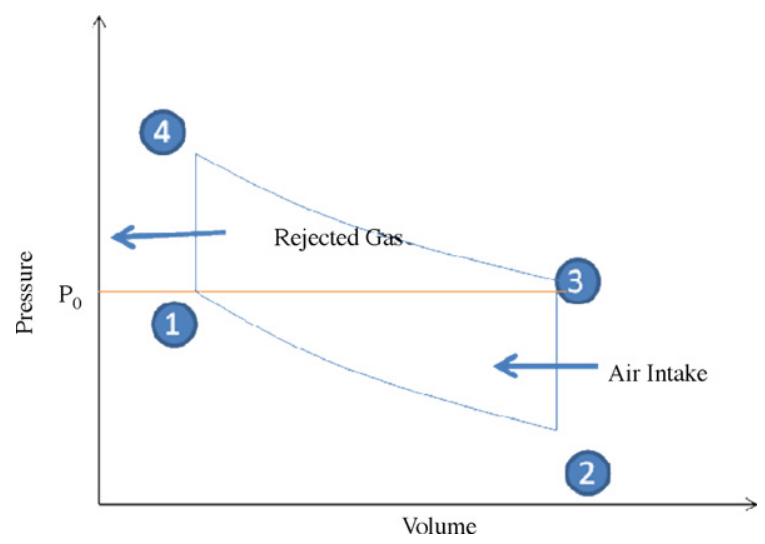

Fig. 3. Pressure-volume diagram of PZT-PEMFC cycle.

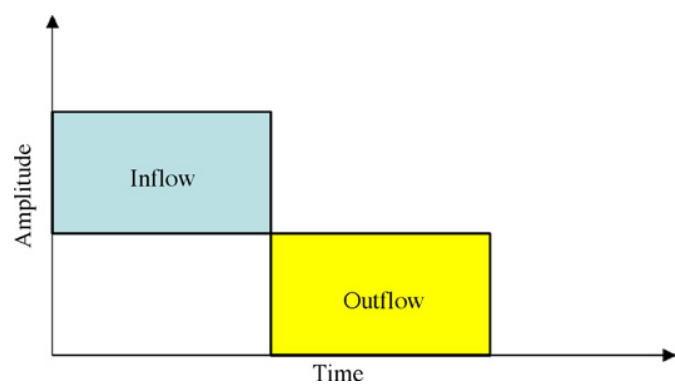

Fig. 4. The step function of periodical flow at cathode.

Also, the inflow and outflow periods in the channel induced by the step function are shown in Fig. 4. The inlet air-flow rate at the cathode is expressed by the Reynolds transport theorem as

$$
\begin{aligned}
\frac{D M}{D t}= & \frac{D(\rho \forall)}{D t}=\frac{\partial}{\partial t} \int_{\mathrm{C} \forall} \rho d \forall+\int_{\mathrm{CS}, \mathrm{PZT}} \rho \vec{V}_{\mathrm{PZT}} \bullet \vec{n} \mathrm{~d} A \\
& +\int_{\mathrm{CS}, \text { in }} \rho_{\mathrm{c}} \vec{V}_{\mathrm{c}} \bullet \vec{n} \mathrm{~d} A=0
\end{aligned}
$$

The gas density is expressed by the equation of state for an ideal gas:

$\rho_{\mathrm{c}}=\frac{P}{R T}$

Substituting Eq. (3) into Eq. (2), the mass conservation equation is derived as

$\frac{1}{R} \frac{\partial}{\partial t} \int_{\mathrm{C} \forall} \frac{P}{T} \mathrm{~d} \forall+\rho_{\mathrm{cs}, \text { PZT }} \vec{V}_{\mathrm{PZT}} A_{\mathrm{PZT}}-\rho_{\mathrm{c}} \vec{V}_{\mathrm{c}} A_{\text {in }}=0$

The inlet velocity at the cathode, $\vec{V}_{\mathrm{c}}$, is derived in the following equation:

$\vec{V}_{\mathrm{c}}=\frac{1}{\rho_{\mathrm{c}} A_{\text {in }}}\left[\frac{1}{R} \frac{\partial}{\partial t} \int_{\mathrm{C} \forall} \frac{P}{T} \mathrm{~d} \forall+\rho_{\mathrm{CS}} \vec{V}_{\mathrm{PZT}} A_{\mathrm{PZT}}\right]$

\section{Theoretical model for PZT-PEMFC}

A numerical model of the novel fuel cell, based upon the SIMPLEC procedure, has also been developed. The assumptions are as follows:

(1) The reactants and products are treated as ideal gases.

(2) The Stefan-Maxwell equations are applied to multi-species diffusion.

(3) Contacting electric and heat resistances among the channel layer, diffusion layer, catalyst layer, and membrane are ignored.

(4) The Nernst-Planck equation is used for the proton transport through the membrane.

(5) Ohm's law is applied across the entire region of the polarization curve.

(6) The porosity and permeability of the porous media are uniform, and the porous media is isotropic and homogeneous.

(7) The effect of gravity is ignored. 


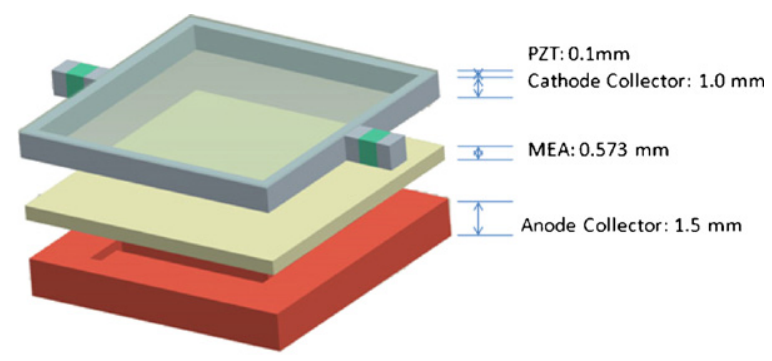

Fig. 5. Dimensions of the air-breathing PZT-PEMFC.

Table 1

Gas composition of fuel and air at inlet conditions

\begin{tabular}{llr}
\hline Fuel & Hydrogen & $73 \%$ \\
& Water vapor & $27 \%$ \\
& Nitrogen & $70 \%$ \\
Air & Oxygen & $25 \%$ \\
& Water vapor & $5 \%$ \\
\hline
\end{tabular}

Unit: molar concentration.

(8) The amplitude of the PZT device is assumed as a constant at different frequencies.

(9) The water existing in the fuel cell is assumed to be $100 \%$ water vapor.

The parameters of MEA refer to a DuPont membrane, and the dimensions of the PEMFC are shown in Fig. 5. The composition of the inlet humidified fuel and air are shown in Table 1. In addition, the inlet fuel velocity is in the range of $0.25-1 \mathrm{~m} \mathrm{~s}^{-1}$. The inlet air velocities vary with different PZT frequencies, which are shown in Table 2.

\subsection{Channel layer}

The governing equations in the channel include the continuity, momentum, and species equations. Since the driving forces of the inlet gas are different at the anode and cathode, the continuity, momentum and energy equations should also be separated into two sides:

\subsubsection{Anode}

The inlet velocity of the anode side is constant, therefore, the continuity equation can be written as

$$
\frac{\partial \rho}{\partial t}+\nabla^{\bullet}\left(\rho \vec{V}_{\mathrm{a}}\right)=0
$$

Table 2

Operating parameters

\begin{tabular}{lll}
\hline \multirow{2}{*}{$\begin{array}{l}\text { Anode } \\
\text { inlet }\end{array}$} & $V_{\mathrm{a}}$ & $0.25 \mathrm{~m} \mathrm{~s}^{-1}$ \\
& $\begin{array}{l}\text { Pressure } \\
\text { Temperature }\end{array}$ & $1 \mathrm{~atm}$ \\
& & $353 \mathrm{~K}$ \\
Cathode & $V_{\mathrm{c}}$ & Eq. (8), $\mathrm{m} \mathrm{s}^{-1}$ \\
inlet & Pressure & $1 \mathrm{~atm}$ \\
& Temperature & $353 \mathrm{~K}$ \\
\hline
\end{tabular}

where $\rho$ is the mixture fluid density, which can be determined by the following equation:

$\rho=\sum_{i=1}^{N} \rho_{i}$

The momentum equation is written as

$\frac{\partial}{\partial t}\left(\rho \vec{V}_{\mathrm{a}}\right)+\left(\nabla^{\bullet} \rho \vec{V}_{\mathrm{a}} \vec{V}_{\mathrm{a}}\right)=-\nabla p+\nabla^{\bullet} \tau$

The energy equation is:

$\frac{\partial}{\partial t}(\rho h)+\nabla^{\bullet}\left(\rho \vec{V}_{\mathrm{a}} h\right)=\nabla^{\bullet} q+\tau: \nabla \vec{V}_{\mathrm{a}}+\frac{\mathrm{d} p}{\mathrm{~d} t}$

where $q$ can be expressed by the following equation:

$q=k_{\mathrm{eff}} \nabla T+\sum_{i=\mathrm{gas}} J_{i} h_{i}$

where $i^{\prime} i / \sigma$ is the generated heat which is induced by the current flow.

The species equation is:

$\frac{\partial}{\partial t}\left(\rho Y_{i}\right)+\nabla^{\bullet}\left(\rho \vec{V}_{\mathrm{a}} Y_{i}\right)=\nabla^{\bullet} J_{i}$

where $Y_{i}$ is the mass fractions in the gas phase of the $i$ th species. $J_{i}$ is the diffusive flux which can be expressed by the following equation:

$$
\begin{aligned}
J_{i}= & \rho D_{i, \mathrm{eff}} \nabla Y_{i}+\frac{\rho Y_{i}}{M} D_{i, \mathrm{eff}} \nabla M-\rho M \sum_{j} D_{i, \mathrm{eff}} \nabla Y_{j} \\
& -\rho \nabla M \sum_{j} D_{i, \mathrm{eff}} \nabla Y_{j}
\end{aligned}
$$

where $\rho D_{i, \text { eff }} \nabla Y_{i}$ is the Fickian diffusion coefficient, which is induced by concentration difference. Other terms are the corrections for multiple species within the porous medium. The fluid diffusion coefficient should be modified to $D_{i \text {,eff, which is }}$ derived by Bruggeman. [32]

\subsubsection{Cathode}

Most governing equations for the cathode channel are similar to the ones for the anode channel. However, the driving force of the cathode gas is given by the PZT. Therefore, the continuity, momentum, energy and species equations in the cathode channel should be modified as follows:

$\frac{\partial \rho}{\partial t}+\nabla^{\bullet}\left(\rho \vec{V}_{\mathrm{c}}\right)=0$

$\frac{\partial}{\partial t}\left(\rho \vec{V}_{\mathrm{c}}\right)+\left(\nabla^{\bullet} \rho \vec{V}_{\mathrm{c}} \vec{V}_{\mathrm{c}}\right)=-\nabla p+\nabla^{\bullet} \tau$

$\frac{\partial}{\partial t}(\rho h)+\nabla^{\bullet}\left(\rho \vec{V}_{\mathrm{c}} h\right)=\nabla^{\bullet} q+\tau: \nabla \vec{V}_{\mathrm{c}}+\frac{\mathrm{d} p}{\mathrm{~d} t}$

$\frac{\partial}{\partial t}\left(\rho Y_{i}\right)+\nabla^{\bullet}\left(\rho \vec{V}_{\mathrm{c}} Y_{i}\right)=\nabla^{\bullet} J_{i}$ 


\subsection{Diffusion layer}

For porous media, the governing equations should be modified by the porosity, $\varepsilon$, and permeability, $k$ of the media. The governing equations are as follows:

\subsubsection{Anode}

3.2.1.1. Continuity equation. The inlet velocity of the anode side is constant, therefore, the continuity equation can be written as

$\frac{\partial}{\partial t}(\varepsilon \rho)+\nabla^{\bullet}\left(\varepsilon \rho \vec{V}_{\mathrm{a}}\right)=0$

The momentum equation is:

$\frac{\partial}{\partial t}\left(\varepsilon \rho \vec{V}_{\mathrm{a}}\right)+\left(\nabla^{\bullet} \varepsilon \rho \vec{V}_{\mathrm{a}} \vec{V}_{\mathrm{a}}\right)=-\varepsilon \nabla p+\nabla^{\bullet}(\varepsilon \tau)+\frac{\varepsilon^{2} \mu \vec{V}_{\mathrm{a}}}{k}$

where $\varepsilon^{2} \mu \mathrm{V} \mathrm{k}^{-1}$ is Darcy's drag force describing the fluid flowing through the porous media. The mixture viscosity is $\mu$, which can be determined by the following equation

$\mu=\sum_{i=1}^{N} Y_{i} \mu_{i}$

where $\operatorname{sub}_{i}$ is the fluid species, and $Y_{i}$ and $\mu_{i}$ are the mass fraction and viscosity of the $i$ th species, respectively.

The energy equation is written as

$\frac{\partial}{\partial t}(\varepsilon \rho h)+\nabla^{\bullet}\left(\varepsilon \rho \vec{V}_{\mathrm{a}} h\right)=\nabla^{\bullet} q+\varepsilon \tau: \nabla \vec{V}_{\mathrm{a}}+\varepsilon \frac{\mathrm{d} p}{\mathrm{~d} t}-j_{T} \eta+\frac{i^{\bullet} i}{\sigma}$

The species equation is:

$\frac{\partial}{\partial t}\left(\varepsilon \rho Y_{i}\right)+\nabla^{\bullet}\left(\varepsilon \rho \vec{V}_{\mathrm{a}} Y_{i}\right)=\nabla^{\bullet} J_{i}$

\subsubsection{Cathode}

The cathode inlet velocity is affected by the PZT device. Thus, the continuity, momentum, energy, and species equations are shown as

$\frac{\partial}{\partial t}(\varepsilon \rho)+\nabla^{\bullet}\left(\varepsilon \rho \vec{V}_{\mathrm{c}}\right)=0$

$\frac{\partial}{\partial t}\left(\varepsilon \rho \vec{V}_{\mathrm{c}}\right)+\left(\nabla^{\bullet} \varepsilon \rho \vec{V}_{\mathrm{c}} \vec{V}_{\mathrm{c}}\right)=-\varepsilon \nabla p+\nabla^{\bullet}(\varepsilon \tau)+\frac{\varepsilon^{2} \mu \vec{V}_{\mathrm{c}}}{k}$

$\frac{\partial}{\partial t}(\varepsilon \rho h)+\nabla^{\bullet}\left(\varepsilon \rho \vec{V}_{\mathrm{c}} h\right)=\nabla^{\bullet} q+\varepsilon \tau: \nabla \vec{V}_{\mathrm{c}}+\varepsilon \frac{\mathrm{d} p}{\mathrm{~d} t}-j_{T} \eta+\frac{i^{\bullet} i}{\sigma}$

$\frac{\partial}{\partial t}\left(\varepsilon \rho Y_{i}\right)+\nabla^{\bullet}\left(\varepsilon \rho \vec{V}_{\mathrm{c}} Y_{i}\right)=\nabla^{\bullet} J_{i}$

\subsection{Catalyst layer}

The important governing equations in the catalyst layer are the species and current conservation equations. Since the chemical reaction and current generation take place in this layer, the species and current conservation equations should be written as below.
The species equation is:

$\frac{\partial}{\partial t}\left(\varepsilon \rho Y_{i}\right)+\nabla^{\bullet}\left(\varepsilon \rho \vec{V} Y_{i}\right)=\nabla^{\bullet} J_{i}+\omega_{i}$

where $\omega_{i}$ is the production rate during the gas phase of the $i$ th species.

In electrochemical reactions, the production rate of each species in the gas phase can be expressed as

$\omega_{i}=\left(a_{i}^{\prime \prime}-a_{i}^{\prime}\right) \frac{j_{\mathrm{T}}}{F}$

where $\alpha_{i}$ is the concentration exponent and the transfer current $j_{\mathrm{T}}$ can be expressed by Butler-Volmer equation as in Eq. (28)

$j_{\mathrm{T}}=\frac{j_{0}}{\prod_{k=1}^{N}\left[\Lambda_{k, \mathrm{ref}}\right]^{\alpha_{k}}}\left[\exp \left(\frac{\alpha_{a} F}{R T} \eta\right)-\exp \left(\frac{\alpha_{c} F}{R T} \eta\right)\right] \prod_{k=1}^{N}\left[\Lambda_{k}\right]$

where $\eta$ is an over potential, which is the difference between the solid potential $\varphi_{\mathrm{s}}$ and the porous (or liquid) potential $\varphi_{\mathrm{F}}$.

A set of non-linear equations for mass-fractions at the porecatalyst interface can be obtained by substituting Eqs. (27) and (28) into the following equation:

$\omega_{i}=\rho D_{i} \frac{Y_{f, i}-Y_{c, i}}{\delta}\left(\frac{A}{V}\right)_{\mathrm{eff}}$

Since the volume of the catalyst layer is much smaller than the entire fuel cell, the effective surface-to-volume ratio, $[A / V]_{\text {eff }}$, should be considered. However, the gas-production rate, $\omega_{i}$, is only applicable in the catalyst layer and when the other $\omega_{i}$ 's are 0 .

The current conservation equation is given by:

$\nabla \bullet i=0$

Since the current flows through the porous medium, the current can be divided into two parts:

$i=i_{\mathrm{f}}+i_{\mathrm{s}}$

where $i_{\mathrm{f}}$ is the current flowing through the fluid and $i_{\mathrm{s}}$ is the current flowing through the solid. Since they are porous mediums, the electrons transfer from fluid to solid and solid to fluid. Thus, the transfer current can be written in the following equation:

$j_{\mathrm{T}}=\nabla \bullet i_{\mathrm{s}}=-\nabla \bullet i_{\mathrm{f}}$

From Ohm's law, Eq. (32) can also be changed to:

$\nabla^{\bullet}\left(\sigma_{\mathrm{f}} \nabla \varphi_{\mathrm{f}}\right)=-\nabla^{\bullet}\left(\sigma_{\mathrm{s}} \nabla \varphi_{\mathrm{s}}\right)=j_{\mathrm{T}}$

\section{Results and discussion}

A novel design of PZT-PEMFCs has been developed and a three-dimensional, transitional model has been successfully built to account for its major phenomena and performance.

\subsection{Pressure field analysis}

The pressure distribution of the cathode channel in an airbreathing PZT-PEMFC is shown in Fig. 6. The expansion 


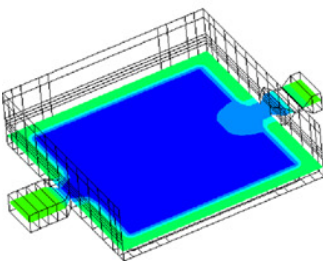

Process 1 - 2

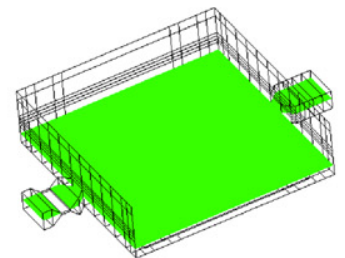

Process 2 - 3

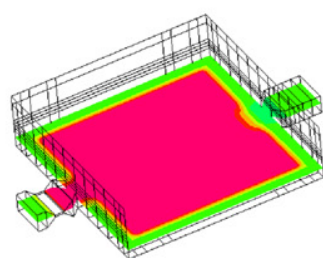

Process 3 - 4

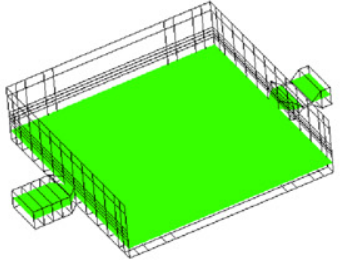

Process 4 - 1

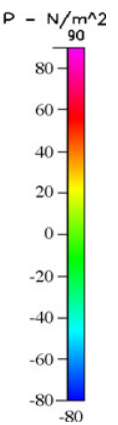

Fig. 6. Pressure distribution of the cathode channel in the PZT-PEMFC.

pressure in process $1-2$ reaches $\left(P_{0}-80\right) \mathrm{N} \mathrm{m}^{-2}$ at the cathode channel. In process $2-3$, air is sucked into the cathode channel until the pressure increases to $P_{0}$. In the compression process $3-4$, the pressure reaches $\left(P_{0}+90\right) \mathrm{N} \mathrm{m}^{-2}$, which compresses more oxygen into the catalyst layer, and thus enhances the chemical reaction rate. In process $4-1$, the produced water vapor and un-reacted reactants are pumped out until the channel pressure is reduced to $P_{0}$.

\subsection{Piezoelectric effect on oxygen profile}

At high PZT frequencies $(f=8,16 \mathrm{~Hz})$, oxygen input is much higher than at low PZT frequencies $(f=1,2 \mathrm{~Hz})$. In general, the higher the frequency, the more air is sucked into the cathode channel. High-consumption rates ( $98 \%$ and $87 \%$ ) of oxygen occur at low frequencies $(f=1,2 \mathrm{~Hz})$ owing to a deficient oxygen input, as shown in Fig. 7. In contrast, low-consumption rates (47\% and 29\%) take place at high frequencies $(f=8,16 \mathrm{~Hz})$ due to an excess supply of oxygen. Thus, a higher PZT frequency $(f=16 \mathrm{~Hz})$ causes a higher concentration of oxygen at the cathode channel, as is shown in Fig. 8. This means that the oxygen at the cathode is rich and actually leads to higher hydrogen consumption and better fuel cell performance.

\subsection{Piezoelectric effect on water vapor profile}

At low frequencies $(f=1,2 \mathrm{~Hz}), \mathrm{PZT}$ actuation leads to current output vibration, drained water vapor fluctuation, and low hydrogen consumption. At $f=1 \mathrm{~Hz}$, most of the water vapor drains out during the first compression due to the initial condi-

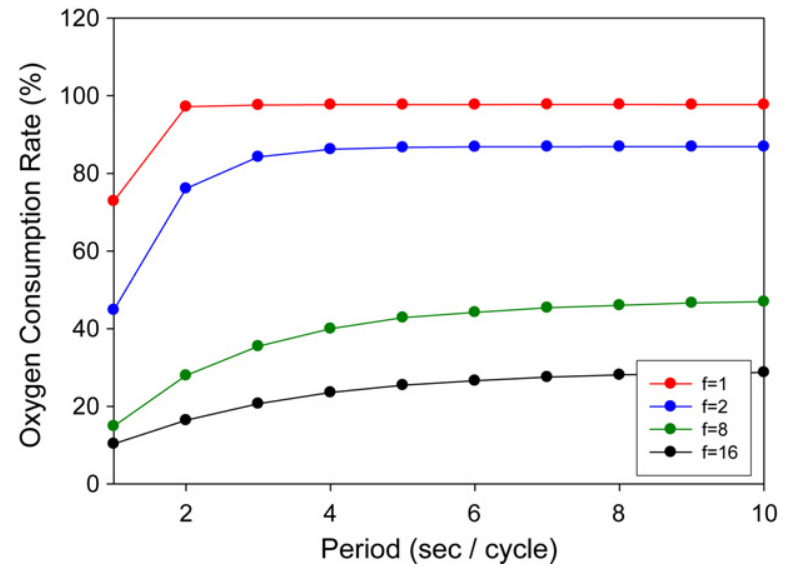

Fig. 7. Oxygen consumption profiles under different PZT frequencies $(0.7 \mathrm{~V})$.

tions, as shown in Fig. 9(a). However, Fig. 9(b) shows a different trend at $f=2 \mathrm{~Hz}$, where the maximum PZT compression and the maximum current generation occur at the same time. Meanwhile, the water vapor produced in the first period cannot be completely drained, so the remainder of the produced water vapor is left for the second period, which appears to have a higher gas output.

At high PZT frequencies $(f=8,16 \mathrm{~Hz})$, more water vapor is produced due to an excess in oxygen input. However, a major portion of the produced water vapor can be drained out of the cathode channel by PZT actuation, which immediately leads to a low water vapor concentration at the cathode, as shown in Fig. 10.

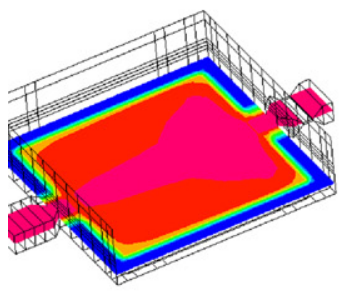

Process 1 - 2

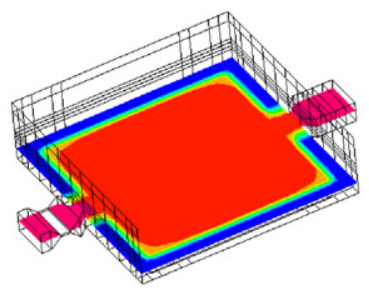

Process 2 - 3

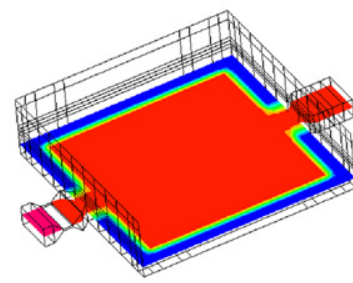

Process 3 - 4

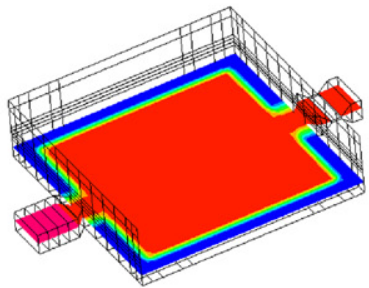

Process 4 - 1

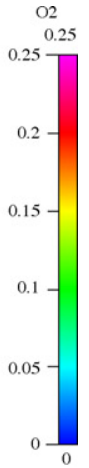

Fig. 8. Oxygen field at $f=16 \mathrm{~Hz}$. 


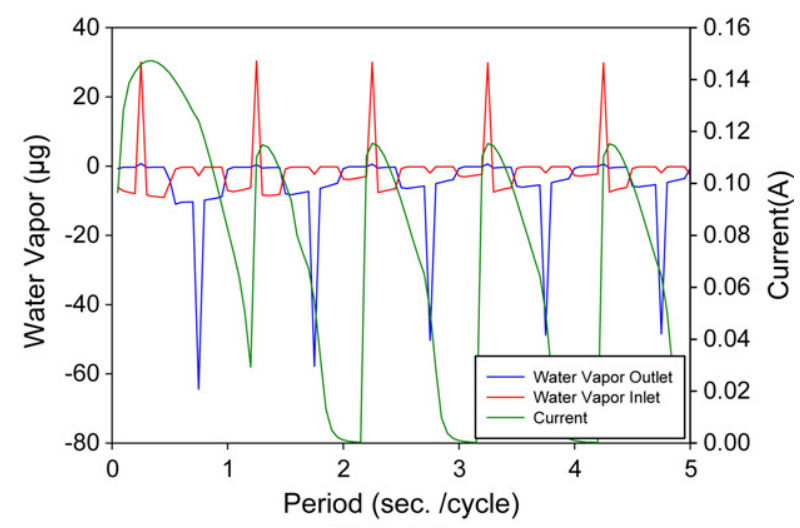

(a) $f=1 \mathrm{~Hz}$

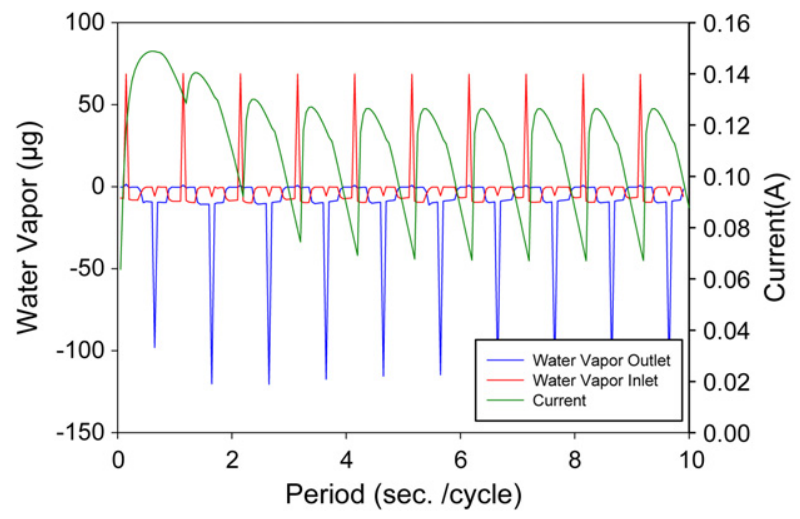

(b) $f=2 \mathrm{~Hz}$

Fig. 9. The current and mass flow rate of water vapor at cathode inlet and outlet $(0.7 \mathrm{~V})$.

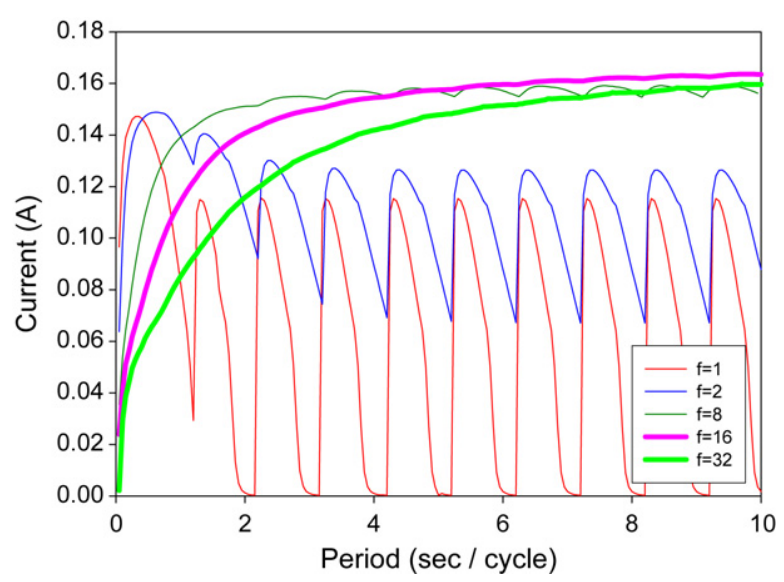

Fig. 12. Current profiles with period at different PZT frequencies $(0.7 \mathrm{~V})$.

\subsection{The current density at different PZT frequencies}

From a polarization curve diagram at low frequency, as shown in Fig. 11, most current losses occur in the region of concentration losses due to insufficient oxygen at the cathode channel. Therefore, a higher frequency of PZT has to supply sufficient oxygen to the cathode channel. In addition, high PZT frequencies generate a stable current, which overcome the concentration losses and eliminate current fluctuation. Hence, the PZT-PEMFC generates higher current density at $f=16 \mathrm{~Hz}$.

For high PZT frequencies, the limited current is $0.35 \mathrm{~A}$ at $V_{\mathrm{a}}=0.25 \mathrm{~m} \mathrm{~s}^{-1}$, and the hydrogen consumption rate is high, which leads to concentration losses and hydrogen deficiency;

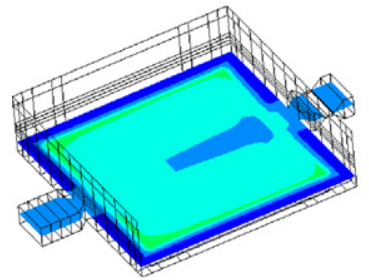

Process 1 - 2

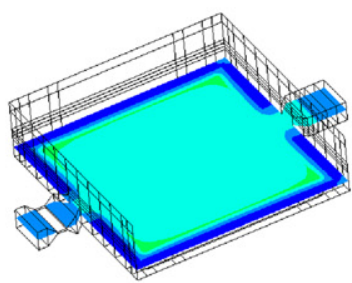

Process 2 - 3

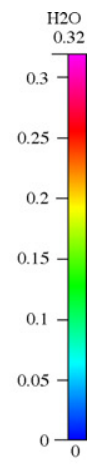

Process 4 - 1

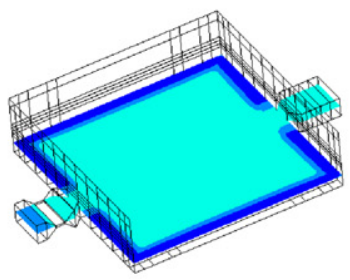

Process 3 - 4

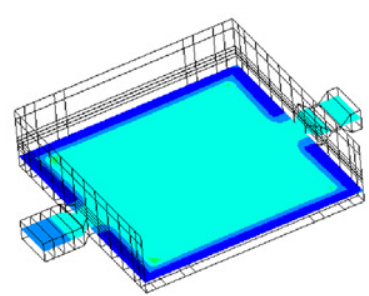

Fig. 10. The water vapor field at $f=16 \mathrm{~Hz}$

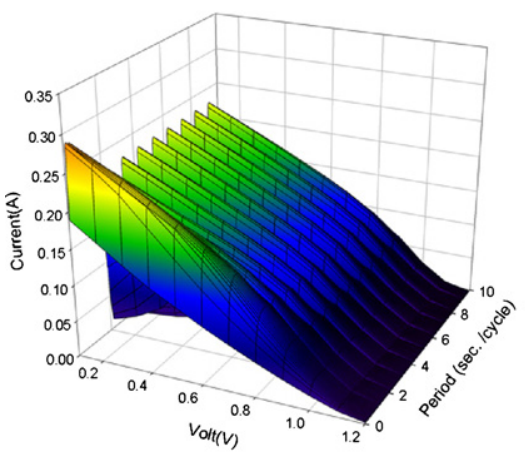

(a) $f=2$

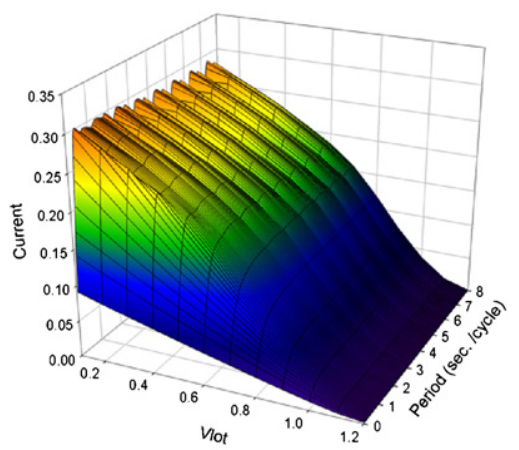

(b) $\mathrm{f}=8$

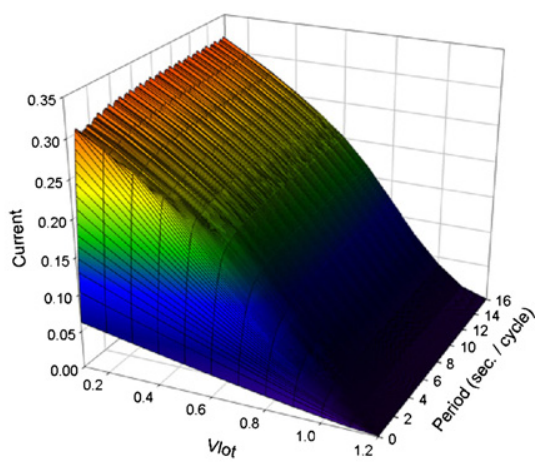

(c) $f=16$

Fig. 11. Polarization $(I-V)$ curves under different PZT frequencies. 
that is, hydrogen input increment can alleviate the concentration losses.

Although the PZT frequencies at $f=16,32 \mathrm{~Hz}$ are high enough to supply more oxygen to the cathode channel, the current generation is limited by the hydrogen supply. In Fig. 12, the optimal operation condition, in terms of maximum current, is $0.17 \mathrm{~A}$ at $f=16 \mathrm{~Hz}$, under $0.7 \mathrm{~V}$, with a hydrogen inlet velocity of $0.25 \mathrm{~m} \mathrm{~s}^{-1}$. Since the hydrogen is insufficient at $f=32 \mathrm{~Hz}$, increasing the PZT frequency fails to enhance the performance any further.

\section{Conclusions}

A novel design of PZT-PEMFCs has been developed and a three-dimensional, transitional model has been successfully built to account for its major phenomena and fuel cell performance. The major findings are as follows:

1. The air-standard PZT-PEMFC cycle is proposed to describe an air-breathing PZT-PEMFC.

2. The PZT-PEMFC, operating in hydrogen-lean conditions, compresses more oxygen into the catalyst layer, and thus enhances the chemical reaction resulting in a higher current output. At the same time, produced water vapor is pumped out from the cathode channel during the compression process.

3. At low frequencies $(f<8 \mathrm{~Hz})$, PZT actuation leads to current output vibration, drained water vapor fluctuation, and low hydrogen consumption.

4. At high frequencies $(f>8 \mathrm{~Hz})$, PZT actuation leads to a more stable current output, drained water, sucked oxygen, higher hydrogen consumption, and also overcomes concentration losses.

5. The optimal operation condition, in terms of the maximum current, is $0.17 \mathrm{~A}$ at $f=16 \mathrm{~Hz}$, under $0.7 \mathrm{~V}$, and with a hydrogen inlet velocity of $0.25 \mathrm{~m} \mathrm{~s}^{-1}$.

\section{Acknowledgement}

This research was funded by the National Science Council of the Republic of China (NSC 96-2221-E-002-074-MY2)

\section{References}

[1] Y. Wang, M. Ouyang, J. Power Sources 164 (2007) 721-729.
[2] D.T. Santa Rosa, D.G. Pinto, V.S. Silva, R.A. Silva, C.M. Rangel, Int. J. Hydrogen Energy 32 (2007) 4350-4357.

[3] Y. Zhang, A. Mawardi, R. Pitchumani, J. Power Sources 173 (2007) 264-276.

[4] L. Matamoros, D. Bruggemann, J. Power Sources 173 (2007) 367-374.

[5] S.U. Jeong, E.A. Cho, H.J. Kim, T.K. Lim, I.H. Oh, S.H. Kim, J. Power Sources 159 (2006) 1089-1094.

[6] S.U. Jeong, E.A. Cho, H.J. Kim, T.K. Lim, I.H. Oh, S.H. Kim, J. Power Sources 158 (2006) 348-353.

[7] S.H. Huang, H.K. Ma, The 2nd International Symposium Thermal Science and Engineering, 2005, pp. 87-91.

[8] H.K. Ma, S.H. Huang, The 4th International Conference on Fuel Cell Science Engineering and Technology, 2006.

[9] X. Li, I. Sabir, Int. J. Hydrogen Energy 30 (4) (2004) 359-371.

[10] M. Koch, N. Harris, A.G.R. Evans, N.M. White, A. Brunnschweiler, Int. Conf. Solid-State Sens. Actuator (1997) 353-356.

[11] B. Li, Q. Chen, D.G. Lee, J. Woolman, G.P. Carman, Sens. Actuator 117 (2) (2004) 325-330.

[12] L. Saggere, N.W. Hagood, D.C. Roberts, H.Q. Li, J.L. Steyn, K. Turner, J.A. Carretero, O. Yaglioglu, Y.H. Su, R. Mlcak, S.M. Spearing, K.S. Breuer, M.A. Schmidt, Applications of ferroelectrics, in: Proceedings of 12th IEEE International Symposium 1, 2000, pp. 297-300.

[13] H. Suzuki, R. Yoneyama, Sens. Actuator 96 (1/2) (2003) 38-45.

[14] E. Stemme, G. Stemme, Sens. Actuator 39 (2) (1993) 159-167.

[15] A. Olsson, G. Stemme, E. Stemme, Sens. Actuator 57 (2) (1996) 137-143.

[16] A. Olsson, G. Stemme, E. Stemme, Sens. Actuator 84 (1/2) (2000) 165-175.

[17] W.L. Benard, H. Kahn, A.H. Heuer, M.A. Huff, J. Microelectromech. Syst. 7 (2) (1998) 245-251.

[18] O. Francais, I. Dufour, E. Sarraute, J. Micromech. Microeng. 7 (1997) $183-185$.

[19] A. Olsson, P. Enoksson, G. Stemme, E. Stemme, Int. Conf. Solid-State Sens. Actuator, 1995, pp. 291-294.

[20] H. Takao, K. Miyamura, H. Ebi, M. Ashiki, K. Sawada, M. Ishida, Int. Conf. Solid-State Sens. Actuator Microsyst., 2003, pp. 139-142.

[21] S. Böhm, W. Olthuis, P. Bergveld, Sens. Actuator 77 (1999) 223-228.

[22] X. Ying, Z. Zhou, H. Cho, X. Luo, Sens. Actuator A 130/131 (2006) 531-536.

[23] H.K. Ma, B.R. Hou, C.Y. Lin, J.J. Gao, M.C. Kou, International Conference on Design Test Integration and Packaging of MEMS/MOEMS, 2007, pp. 273-278.

[24] H.K. Ma, B.R. Hou, H.Y. Wu, C.Y. Lin, J.J. Gao, Microsyst. Technol., doi:10.1007/s00542-007-0462-6.

[25] J.S. Yi, T.V. Nguyen, J. Electrochem. Soc. 145 (1998) 1149-1159.

[26] S.H. Ge, B.L. Yi, J. Power Sources 124 (2003) 1-11.

[27] T.F. Fuller, J. Newman, J. Electrochem. Soc. 139 (1992) 1332-1337.

[28] T.A. Zawodzinski, J. Davey, J. Valerio, S. Gottesfeld, Electrochim. Acta 40 (1995) 297-302.

[29] S.H. Ge, B.L. Yi, P.W. Ming, J. Electrochem. Soc. 153 (2006) A1443-A1450.

[30] M. Ise, K.D. Kreuer, J. Maier, Solid State Ionics 125 (1999) 213-223.

[31] CFD-ACE, CFD Research Corporation (2004).

[32] V. Gurau, H. Liu, S. Kakac, AICHE J. 44 (11) (1998) 2410-2422. 